\title{
Research on College Physical Education Teaching Collaborative Innovation and Resources Sharing
}

\author{
Zhong Pengfei \\ Department of Physical Educations, Wuhan University of Technology, Wuhan, China
}

\section{Email address:}

zhongpengfei@whut.edu.cn

\section{To cite this article:}

Zhong Pengfei. Research on College Physical Education Teaching Collaborative Innovation and Resources Sharing. Science Innovation. Vol. 5, No. 3, 2017, pp. 187-193. doi: 10.11648/j.si.20170503.21

Received: March 30, 2017; Accepted: April 24, 2017; Published: May 4, 2017

\begin{abstract}
According to the general requirements of the ministry of education "quality project", this paper analysis the college sports curriculum collaborative innovation of strategic opportunity, classifying education college sports curriculum resources, put forward the path choice of college sports curriculum collaborative innovation, construction of college sports curriculum the collaborative innovation leadership and organization, teacher's ability to ascend and teaching innovation platform, the teaching achievements of research and development and the achievement transformation platform, communication platform, network teaching platform, cultural inheritance, innovation platform, establish college sports curriculum resources mutual recognition of credits, borrowed each other's teacher, near to the common and complementary, network communication mode of resource sharing, to lead the mechanism innovation of university physical education curriculum reform.
\end{abstract}

Keywords: The University Physical Education Curriculum, Collaborative Innovation, Resource Sharing

\section{大学体育课程教学的协同创新与资源共享研究}

\section{仲鹏飞}

武汉理工大学体育部, 武汉, 中国

\section{邮箱}

zhongpengfei@whut.edu.cn

摘要: 本文依据教育部《质量工程》总体要求, 分析研究高校大学体育课程教学协同创新的战略机遇, 对大学体育课 程教育资源进行系统分类, 构建中国大学体育课程教学协同创新的选择路径, 打造大学体育课程协同创新领导与组织 平台、教师能力提升与教学创新平台、教学研发和成果转化平台、成果交流平台、网络教学平台、文化传承创新平台, 确立大学体育课程教学资源校际间学分互认、名师互借、近邻共用、投入互补、网络互通的资源共享模式, 旨在引领 大学体育课程改革的机制创新。

关键词: 大学体育课程, 协同创新, 资源共享

\section{1. 引言}

大学体育课程是中国所有高校开设的一门公共必修 课程。由于各所高校大学体育的教学条件不同、教学内容
不同, 导致教学效果相差很大, 为了充分发挥高校大学体 育课程的资源优势, 提高大学体育课程的教学质量, 实现 高校之间优势互补, 要积极建立大学体育课程教育的协同 创新机制, 推动高校之间的深度合作, 实现高校大学体育 
课程教学资源共享, 从而达到满足提高学生运动能力、增 强学生身体素质和社会适应能力的教学目的。

\section{2. 高校大学体育课程教学协同创新的战略机遇}

\section{1. 国家科技创新战略要求高校推进协同创新}

《国家中长期教育改革和发展规划纲要 (2010-2020 年)》明确提出了推动高校协同创新的要求。高校应抢抓 机遇, 顺势而为, 瞄准科技发展前沿, 推进协同创新战略, 以高水平的科学研究支撑高质量的人才培养, 在创新型国 家建设中担当更大重任。高校之间需要协同创新来促进与 社会发展的相适应, 只有这样才能充分发展高校的创新能 力, 集中高校的这些创新能力建立起高校间的战略联盟, 由此来促进高校丰富资源的有效共享。

教育部、财政部联合下发了一系列的文件, 旨在更好 的推动我国教育事业的有效发展。创新能力是国际竞争力 的核心要素, 为了在国际竞争中赢得主动权, 依靠科技创 新来提升国家的综合实力和核心竞争力, 建立国家创新体 系, 走创新型国家之路, 成为我国的重要战略选择。

\section{2. 高等教育快速发展要求高校创建协同创新}

当今, 我国的高等教育事业取得了快速的发展, 高校 应该把提高教学质量放在高校发展的首要位置, 增加学生 的知识含金量, 培养社会需要的高素质人才, 在抓教学质 量的同时也要注重高校的全面协调发展, 要以服务社会、 满足学生需求为宗旨, 办社会需要、学生满意的高校, 促 进高校教育新体系的构建与有效发展。

中国的高等院校、科研机构设置全面, 但是没有形成 协同研究体系, 都各自为政分散研究, 成果凌乱, 相互之 间的沟通联系很少，导致了资源的严重浪费。我国高校作 为高水平人才的第一输出地, 肩负着提供优质人才的重任, 但是人才培养与科技发展出现了一定的脱节 [1]. 作为科 研的核心机构之一, 面对国家的科技创新战略需求, 高校 应该放开门户之见, 与其它高校、科研、创新机构开展交 流合作, 提高创新能力, 促进资源的有效利用, 促进教育 与科技的有机结合，最终提高国家的综合实力。高校之间 的协同创新战略实施, 可以很好的适应经济社会人才发展 的需求。充分发挥各高校协同创新的资源, 将其进行充分 的整合, 以经济社会人才的发展需求为目标, 加强对拔尖 创新人才的培养, 进一步缩小我国与世界先进水平人才之 间的差距, 推动人才强国战略的发展 [2]。

建立世界高水平大学, 首先要顺应社会的发展, 对国 家急需的战略性需求进行研究, 大力推进协同创新战略, 促进高校之间的有效联合, 组织创新团队来加强创新平台 的建设, 以高水平的研究作支撑来提高我国教育事业的发 展, 这是高等教育发展的必然要求。

\section{3. 大学体育课程改革要求高校实施协同创新}

中国教育部 “质量工程” 把课程、教材建设与资源共 享建设放在突出的地位, 其目的是为了进一步推进在人才 培养模式、课程教材体系、专业结构设置等方面的改革,
培养创新型人才。大学体育课程协同创新, 旨在形成 “以 人为本、健康第一” 的课程教育体系, 为了拓展体育的功 能, 发挥高校大学体育课程的优势, 就必须充分整合各校 的优质体育教育资源, 最大限度地发挥教师的特长, 使体 育学科的最新成果被及时补充到课程教学中, 优化高校师 资队伍结构、更新大学体育教学内容、创新大学体育教学 方法, 形成多种媒体形式的立体化教材 [3]。

从大学体育课程教学资源协同创新战略实施的意义、 基本条件、程序入手确定其教学资源共享原则, 探索其协 同创新的共享途径, 力图构建大学体育课程教学资源共享 平台与监测体系, 建立高校间协同创新的战略联盟, 促进 高校之间优势资源的强强联合, 实现高校之间的优势互补, 从而有效推动高校大学体育课程教学资源的创新共建与 资源共享。

\section{3. 高校大学体育课程教育资源的分类与功能}

\section{1. 大学体育课程教育资源的分类}

体育资源是人们从事体育生产或体育活动所利用或 可资利用的各类条件及要素。体育资源分为体育自然资源 (地理环境资源、气候条件资源)、体育社会资源 (体质资 源、科技资源、教育资源、经济资源、物质资源、民族资 源、传统资源）。体育资源包括两类：第一类是有形的物 质资源 (有固定的物质形态, 自然界存在的或人为创造的, 可作为体育产品生产的物质要素及必须的环境条件）。第 二类是无形的非物质资源 (没有固定的物质形态, 如社会、 经济、技术因素中可用于体育服务产品的各类要素, 主要 有体育科学理论、训练技术、体制、道德法规、民俗、经 济条件等）。

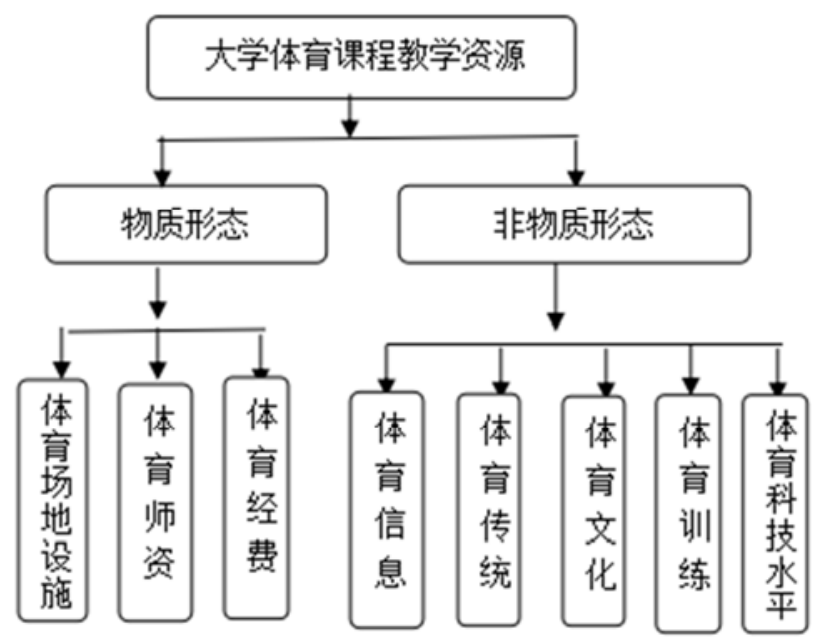

图1 大学体育课程教学资源分类。

我们将大学体育教育资源分为五大类。第一类: 体育 人力资源（体育教师、体育管理者、体育教辅人员）。第 二类：体育财力资源（政府投入、社会捐助、自我开发盈 利）。第三类：物力资源（体育场地、体育器材）。第四 类：体育信息资源（体育报纸、体育杂志、体育类图书、 
网络资源、体育传媒）。第五类：体育时间资源（早操、 课间操、体育课、课外活动、体育竞赛、课余训练）。

\section{2. 大学体育课程教育资源的功能}

体育人力资源指在学校体育系统内具有教育教学、科 研和管理能力全部人口的总和, 主要由管理人员、教学科 研人员、教辅人员三部分组成。人力资源是所有资源中的 首要资源、第一资源。体育人力资源能够很好地完成学校 日常的教学、训练科研工作, 还能够承担体育理论培训、 技术辅导、健康、康复咨询等为社会提供优质服务方面的 工作。

体育财力资源指政府、社会为学校体育发展提供必要 的经济支持, 是开展学校体育各项工作的基础, 是保证学 校体育事业顺利发展的重要因素之一, 学校体育资源的经 济支柱 [4]。

体育物力资源指比较规范的体育场地、健身体育活动 场馆、体育器材等设施。实现学校体育目的和任务的物质 基础, 为运动健身提供锻炼场所和运动健身器材。

体育信息资源是指反映体育事业这个特定事物特征 及其发展变化情况的各种消息的总和。从广义上讲, 又指 一切可以向体育事业提供信息的消息和资料。体育信息包 括体育及其有关的消息、情报、指令、决策、信号、资料 等。体育信息是体育决策和规划的基础, 是发展体育事业 的依据, 体育系统与社会的沟通必须借助体育信息 [5]。

体育组织机构是为保证学校体育工作的顺利开展和 实施独立的办公机构, 是学校体育管理者的办公场所, 是 体育教师组织上课、备课的场所。

学校体育时间资源是学校师生进行体育技能学习、身 体锻炼、体育活动最基本的时间保证。学校时间资源能为 学生提供体育活动所必需的时间, 同时也是学校各项体育 活动顺利开展的时间保证, 为学校体育活动开展提供空间, 是学校体育活动顺利进行的保证。

学校体育资源的主要功能: 第一, 学校体育人力资源 具有教育功能; 第二, 学校体育物力资源是进行体育健身 的物质基础; 第三, 学校体育信息资源具有传播功能; 第 四，学校体育时间资源具有提供锻炼空间的功能。

\section{3. 构建大学体育课程教育资源的规范的管理体系}

制度是要求大家共同遵守的办事规程或行动准则。体 育大课程体系涵盖的范围很广, 就高校内部来说, 不仅有 体育部门、各二级教学院系的体育, 也有高校各处室的体 育 $[6]$ 。

从管理学的角度来说, 相应的体育管理制度能有效的 提高体育教学的质量。高校的体育制度既包括体育部门的 管理制度, 也包括工会以及各二级教学院系的体育管理制 度。促进体育大课程体系建设, 应建立健全学院体育管理 制度, 用体育制度引导各部门引导各部门在体育工作的协 作, 通过体育制度, 引导各部门和广大教职员工重视体育, 营造浓郁的校园体育文化氛围, 实现校园体育全民参与、 全员育人的目标。

\section{4. 大学体育课程教学协同创新的路径选择}

\section{1. 大学体育课程教学协同创新策略}

\section{1. 1. 签订高校战略联盟, 做好顶层设计}

高校作为推进协同创新的重要力量, 应着眼于提高我 国自主创新能力和水平, 协助国家从战略的高度做好顶层 设计, 争取各级政府的政策和资金支持, 调动其他创新主 体的积极性和创造性, 促使协同创新按既定的路线图推进, 有效实现预期目标。发挥教育行政主管部门的优势（教育 厅）, 根据高校大学体育课程教学资源布局情况, 做好顶 层设计, 组织高校体育主管部门(学校体育运动委员会), 签订大学体育课程教学创新的战略联盟, 集中优势资源大 力协同创新开展深度合作, 建立战略联盟, 促进优质资源 共享 [7]。

各省教育行政主管部门 (教育厅) 要积极健全协同创 新的规章制度，提升协同创新的操作力。做到创新团体的 创新成果与效益挂钩, 加强制度建设与制度创新, 构建有 利于保障协同创新工作有序推动、科学合理和切实可行的 管理制度体系, 建立科研资源配置与共享、科研成果收益 分配与共享等制度, 充分调动大学体育创新团队与创新人 才主动参与研究的积极性、创造性。

为全面推进教师教育的改革与创新, 实现教师教育研 究与实践成果共享, 2012年12月29日, 由山东19所省属师 范院校在济南成立山东省高等学校教师教育联盟。成立教 师教育联盟有助于高校增进交流合作, 整合优势资源, 实 现协同创新。

2010～2019年, 湖北省教育厅组织武汉南湖片区十所 高校实行办学大联盟。根据协议, 十校学生在校期间可在 校际间攻读辅修双学位; 相互选修课程且相互承认学分; 可以有组织地利用其他高校教学实验室和教学基地; 可以 根据需求选派学生在校际间游学; 可优先报考、录取第二 学士学位; 校际间可互聘教师承担普通本科生教学任务。

\section{1. 2. 把握协同创新思想内涵, 促进创新顺利实施}

大学体育课程教学的协同创新是以教师、体育课程、 课程研究三位一体的创新能力提升为核心, 集聚优秀创新 团队、培养优秀创新人才、创造优秀创新成果。大学体育 课程优质教育资源协同创新, 能有效实现体育教育资源的 优化配置, 避免各自办学资源重复配置, 最大限度地发挥 现有人力、物力、财力、信息资源的作用，是提高体育教 育资源利用效率和办学效益的重要途径, 这是落实科学发 展观, 建设节约型社会的必然选择和一项有效措施 [8]。

大学体育课程教学的协同创新有利于促进大学体育 课程优质教育体系的公平与合理。我国高教资源分布不平 衡, 东部地区和西部地区、中心城市和非中心城市的差别 较大, 这种现状制约了部分大学体育课程教学质量的提高, 通过大学体育课程数字化建设和网络平台等现代化信息 技术手段, 使大学体育课程优质教育资源共建共享, 从而 促进高等教育资源配置的公平与合理化 [9]。 


\subsection{3. 打造高端平台团队，保证创新可持续性}

大学体育课程教学的协同创新有利于打造高端平台 团队，促进高校体育教师的教学水平逐步提高。通过大学 体育课程数字化建设, 最大限度地发挥教师的特长, 使体 育学科的最新成果被及时补充到课程教学中, 优化高校师 资队伍结构、更新大学体育教学内容、创新大学体育教学 方法, 形成多种媒体形式的立体化教材 [10]。

大学体育课程教学的协同创新有利于建立大学体育 课程教育资源体系的规范化、科学化、程序化。作为大学 体育课程优质资源共享的基础, 没有统一的标准, 优质资 源的共享将无从作起，因此应从共享的需求出发，尽快整 合、建立和完善相应的国家标准，构建完整的标准体系， 这样才能使各高校体育优质资源共享平台的开放工作更 具规范化、科学化、程序化, 从根本上保证教学和服务的 质量。

\section{2. 大学体育课程教学协同创新的平台构建}

\subsection{1. 大学体育课程协同创新领导与组织平台}

依托教育行政主管部门（教育厅）、各个省市体育单 项协会, 成立大学体育课程协同创新领导与组织机构, 负 责政府教育经费的预算、教学资源整合、各创新团队活动 的组织工作、协调创新教学成果的展示、质量评估、总结 及远景规划 [11]。

\subsection{2. 大学体育教师能力提升与教学创新平台}

体育教师业务能力提升机制建设, 进行人才培养和交 流。整合优化师资资源和教学条件, 针对各类创新主体的 不同需求开展人才培养和培训工作, 为创新主体间的人才 交流提供便利。战略联盟内的高校, 定期开展业务学习活 动, 在教师职业道德、教学能力、教育科研能力等方面得 到发展和提高。

组建体育教学创新团队。组建大学体育同项目教学创 新团队, 比如篮球组、排球组等。组建大学体育不同项目 教学创新团队, 比如教学视频开发组、教学内容创新组等。 可以有同校组建创新团, 也可以不同高校组建创新团队。

\subsection{3. 大学体育课程教学研发和成果转化平台}

集合战略联盟内高校体育教师、体育科研所、视频录 制编辑人员等创新主体对大学体育课程共性关键技术和 前瞻性技术进行协同研发, 构建多元化成果转化与辐射模 式, 带动区域战略联盟内高校大学体育创新成果的发展。

\section{2. 4. 大学体育课程教学成果交流平台}

定期进行大学体育课程教学成果交流、展示和研讨活 动, 比如学生篮球赛、排球赛、定向越野赛等, 取长补短, 互相借鉴, 确立新的教学理念, 完善创新教学体系、内容 和方法, 既是推进高校体育教学改革的举措, 也是体育教 学工作向各战略联盟高校进行汇报, 形成特色的高校体育 文化活动氛围 [12]。

\subsection{5. 大学体育课程教学网络平台}

建立了大学体育课程网络教学课堂, 深化了理论与实 践相结合的过程, 开辟了 “博士在线” 等专栏, 强化了所 学知识的近期和远期实践效应。有效地拓展体育教学网络 互动, 完善体育课程网络视频教学、网上答疑与自我知识 测试、书籍与查询信息等教学辅助的机制。

\section{2. 6. 大学体育课程学术交流和文化传承创新平台}

结合大学体育课程协同创新情况, 定期召开大学体育 课程研究学术交流活动, 积极拓展大学体育课程教学内容, 把民族体育项目补充到学校体育教育中来, 形成大学体育 课程极强的思想性、教育性、竞技性、娱乐性、观赏性、 健身性等价值特点, 探索建立体育文化传承创新的新模式, 提升国家体育文化软实力。

\section{3. 大学体育课程教学资源共享模式}

确立大学体育课程教学资源共享“协同创新、合作 办学、资源共享、协同发展”的指导思想。各高校要更 好的实现资源共享必须先转变思想观念, 从打破校际的 门户之见开始, 积极的把各自的优质资源进行共享, 把 协同创新当作是对各校资源的大整合, 把共享当作是利 用他校优质资源实现与本校资源的互补, 同时提高本校 的知名度、扩大本校影响力, 加强与其它高校之间的协 同创新, 为合作共享提供优质的资源。

\subsection{1. 需求导向, 学分互认}

目前高校积极建立和推行学分制改革, 高校之间学分 互认管理体系, 满足学生的学习需求, 学分制建立是大学 体育课程在不同的高校间学习成为现实。华中科技大学学 生可以到中国地质大学 (武汉) 学习大学体育课程的室内 攀岩项目, 而中国地质大学 (武汉) 学生可以到华中科技 大学学习大学体育课程的壁球项目, 两校之间互任学分。

\subsection{2. 优势互补, 名师互借}

由于各个大学之间体育学科发展水平的不同、师资力 量与水平不同、高校之间实行体育课程教学资源的优势互 补, 是实现 “合作共赢” 的切入点 [13]。互学大学体育教 改经验, 在积累成功经验的同时解决的困难和问题。高校 之间的体育教学名师要互相借用, 促进大学体育课程质量 提高。

\section{3. 3. 相互协调, 近邻共用}

邻近共用原则是指具有地缘优势的高校之间更容易 实现教学资源的共享, 如果在本区域内高校能够获得的资 源就尽量不要舍近求远, 这也是节约成本的做法。邻近共 用原则带给我们的启示就是当前我国高校大学体育课程 教学资源的校际共享首先以区域共享为主, 充分挖掘区域 内的高等教育资源潜力, 构建区域高校大学体育课程教学 资源共享体系或平台, 实现教育资源更大范围的共享。 


\section{3. 4. 共同开发, 投入互补}

共同开发是指高校开发相邻所属共同资源为大学体 育课程教学所用。比如武汉南湖片区有十多所高校, 大家 可以投资开发南湖, 开设大学体育课程水上项目, 比如皮 划艇项目、龙舟项目。投入互补是指具有资源互补性的高 校之间可以或者是容易实现教育资源的共享。所谓的资源 投入互补性是指不同高校所拥有的教学资源在数量以及 质量上能够互相弥补对方的不足的特性。通过互补原则, 一方面可以有效解决资源单一高校面临的资源缺失问题。 另一方面, 可以有效解决资源劣势高校面临的资源质量问 题。

\section{3. 5. 网络互通, 信息共享}

大力推进资源的网络化管理, 加强各校之间资源的网 络共享进程, 是实现高校大学体育课程教学资源有效共享 的必要措施。实现大学体育课程教学资源网络化, 不仅方 便学生对网络体育资源的查阅, 又可以有效的减少各校大 学体育课程教学资源的重复配置。利用互联网可以做到高 校大学体育课程教学资源共享, 可以做到教学视频的同时 共享、异时共享、同地共享、异地共享。如图2所示。

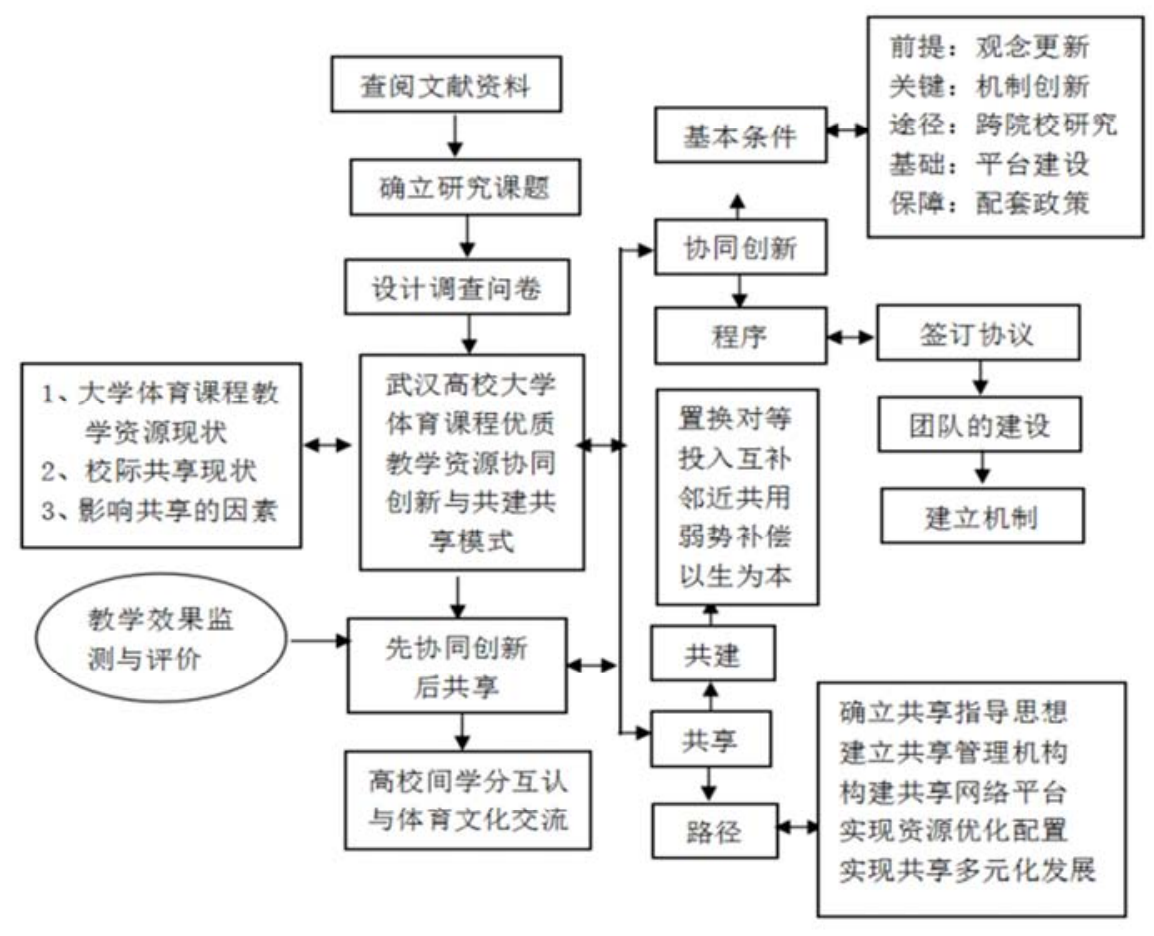

图2 大学体育课程协同创新与共建共享模式示意图。

\section{5. 大学体育课程教学协同创新与资源共享成效}

\section{1. 满足了高校学生学习大学体育的学习需求}

建立以 “互联网+体育” 为核心的大学体育课程教学 环境, 有效地解决教育资源不足的难点, 能更快地帮助学 生建立动作表象、领会动作要领, 激发学生的学习兴趣。 体育教学目标的多元化、课内外一体化, 满足了学生对大 学体育学习的需求, 有利于教学信息多样化, 有利于学习 者的积极参与, 有利于学生获取丰富的信息。高校大学体 育课程教育资源共建共享满足了学生学习体育的选择性, 才能保证学生的主体地位, 满足不同学生个性发展的需求, 从教学思想上有利于因材施教; 从管理制度上有利于建立 学生的主体地位; 从激励机制上有利于调动学生的学习积 极性; 从教学资源配置上有利于教学管理资源的充分使用。

整合高校大学体育课程优质教育资源, 优化高等教育 信息资源配置，实现高等教育信息资源的开放、共享。高 校教育信息资源共享可以避免政府对高等教育的重复投
入, 节省办学经费, 提高办学效益, 使受教育者能平等地 获得受教育和发展的机会, 使教育信息资源得到充分的利 用, 并发挥其最大的教育效益、社会效益和经济效益。学 校既要按照统一的场地器材配备目录进行规范化建设, 又 要力求避免器材过于竞技化, 因校制宜地修旧利废, 营造 健康、环保、有利于学生健康成长的多样化场地设施, 使 学生能够在优美、清洁、轻松、愉悦的氛围中锻炼成长。

\section{2. 促进了高校对课程资源的合理开发}

大学体育课程管理模式的重要特点就是选课, 大学应 该办成 “课程超市”, 满足学生各种求知需求, 尽快 “丰 富货架”, 就必须积极研发大学体育课程教学内容, 开发 学生喜爱的运动项目。首先, 要选择一些以健身、娱乐为 主的项目。男生喜欢的运动项目足球、篮球、游泳、羽毛 球、乒乓球、旱冰、远足。女生喜欢的项目健美操、羽毛 球、体育舞蹈、游泳、篮球。因此, 根据学校的自身实际 情况开设男女生喜欢的项目作为活动课程, 同时对这些运 动项目的难度和精确度加以简化, 让学生在掌握基本动作 
的基础上去享受体育带给他们的快乐。其次, 我国幅员辽 阔, 各民族有自己不同的体育传统, 也可根据地方特色, 选择一些乡土气息浓厚的传统运动项目。例如多山的地带, 选择爬山运动, 东北地区天气寒冷, 选择滑冰运动, 使学 校体育冲破学校的束缚, 与野外自然体育和社会体育相结 合, 让学生充分感受到自然和人文的统一, 进而建立有规 律的运动行为习惯, 不仅锻炼了身体, 陶冶了情操, 提高 了学生适应自然、适应社会的生存能力, 而且使体育更加 乐趣化、生活化、人文化。同时, 开设体育理论课程, 主 要传授体育文化、体育卫生保健、运动项目的竞赛规则和 裁判法以及运动处方和身体素质练习方法。这样有利于学 生掌握科学知识, 提高体育文化素养, 培养学生对体育运 动的鉴赏能力以及锻炼身体的自觉性, 为终身体育打下坚 实的基础。

\section{3. 有利于大学体育课程教学质量的提高}

大学体育课程教育资源共建共享, 可以把各个高校教 师的协同创新与常规教研、日常教学紧密结合, 形成以骨 干教师为主、广大一线教师、专家、学者广泛参与的资源 共建队伍，进而形成分工合作、共同建设、同步共享的资 源建设模式, 在教师教学过程中, 将适合本区域教学特点 的资源不断地积累、丰富, 最终沉淀出优质资源, 达到资 源建设与教学辅助的双效功能, 从而实现区域大学体育教 学资源优势化、产业化、集群化, 形成合力实现资源建设 的 “建享合一”。

高校大学体育课程教育资源共建共享促进了教师业 务水平的提升。现代社会, 知识更新速度加快, 很多体育 教师职前接受到的教育已经很难满足当前体育新课程教 学改革的要求, 体育教师要想跟上时代步伐, 适应社会发 展, 首先一定要树立终身学习的意识, 成为一个终身的学 习者。其次, 要学习现代体育知识, 了解现代体育教育的 新领域、新方向、新成果。并学习掌握现代信息技术, 能 主动地运用计算机, 开发、利用互联网上的体育教育资源。 学分制的实施以及高校体育课程改革更要求教师应具备 这种创新能力, 学分制下学生选择授课教师的方式, 同等 条件下, 显然有创新意识的教师会更受学生的青睐。拓展 大学体育知识教学方法, 对全体学生实施网上理论考试的 教学改革工作, 开发了网络体育理论考试软件, 拓展了体 育理论知识的传播空间, 拓展了学生运动卫生知识、体育 保健知识和运动营养保健知识的范围, 提高了学生对体育 理论的学习兴趣, 降低了教师的工作强度。

\section{4. 实现校际间教师资源共享}

教师资源实现校际共享就是打破传统的师资管理状 态, 杜绝自我封闭, 同时也是摆脱专业结构、职称结构不 均匀分布情况的最佳途径。只有将高校中体育学科带头人、 各骨干教师的潜力充分挖掘, 鼓励他们合理投入部分精力 和时间到其他普通高校通过兼授课程、指导学生、合作科 研等形式, 提高各高校较低层次教师的教学、科研能力, 才能借此改变高校教师不均匀的分布、不合理的结构划分、 人员的不流动以及余缺不互补的现状。
营造校际间课外体育活动良好氛围。大学体育教育在 高校教育中不容忽视, 所以要对校际间课外教育活动和体 育课的关系有正确认识。大学生需要高校为其营造良好的 课外体育活动氛围, 并通过协调配合、统筹兼顾, 引导个 人自发锻炼, 建立健全校际间大学生体育社团组织, 为构 建和谐的体育环境出谋划策, 大力推进大学课外体育活动 的深入开展。吸引大学生广泛参与定期开展校内外有影响、 有组织的课外体育活动, 以此引导其树立健康生活的理念, 养成体育锻炼的良好习惯, 培养其团队合作精神, 使大学 生在开放的复杂社会中学会良性竞争。

\section{5. 促进了大学体育课程的传承创新}

促进了体育文化传承方式的创新。通过大学体育课程 教育资源的协同创新, 构建高校体育教育及体育文化发展 体系, 把民族体育融入大学体育课程之中, 增加中华武术、 中国象棋、舞龙舞狮、求球、扇子舞、太极功夫扇、珍珠 球、巴桑舞等民族体育项目的教学内容, 走进高校走向课 堂, 推广与升华我国民族体育核心价值体系具有极强的思 想性、教育性、竞技性、娱乐性、观赏性、健身性。特别 是互联网技术在大学体育课程教学中广泛应用, 满足大学 生对体育学习与欣赏的客观需求, 丰富和传承我国民族体 育文化体系、体育保健康复体系, 树立大学生以终身健康 为目标的体育观。

促进了体育教学资源共建的创新。实现了大学体育课 程教学中的人力资源、物力资源、课程资源、文化资源、 信息资源五大共享, 提高了学生对大学体育课程的学习兴 趣, 丰富了学习内容, 延长了学习时间、跨越了地理空间, 争取了优势教学资源, 对大学体育校本教程的开发产生积 极的影响。拓展体育的教育功能, 利用互联网搭建大学体 育网络教育平台, 实行优质教育资源共享; 建立和完善健 康、保健与健身处方大学体育教学体系; 建立并实施动态 模式的大学体育课程评估体系与监督机制, 从教材建设、 教学效果、场地条件等方面入手, 由学生、同行和专家进 行量化评价, 达到科学管理的目的。

促进了体育教学体系的创新。在大学体育课程教学改 革中提出协同创新的教育理念, 建立了高校大学体育课程 教育资源共建共享协同创新平台。在大学体育课程体系、 教学内容、教学方法、教学手段、现代技术应用与网络平 台建设、管理创新、质量保障与监控等方面进行共建共享 的探索与实践, 形成了大学体育课程鲜明的身心健康教育 特色, 推出了教育理念、制度创新、课程建设、教学实践 等一系列研究成果, 在国内普通高校具有良好的引领和示 范效应, 具有推广和应用价值。

\section{6. 结论与建议}

\section{1. 结论}

大学体育课程教学协同创新与资源共享, 促进高校体 育教师的优势专业整合, 形成课题攻关团队, 把大学体育 教学内容信息的数字化建设, 实现异地资源共享、实现大 学体育课内外一体化教学模式。大学体育课程协同创新可 以促进学生对大学体育知识的学习, 学生浏览网络量、知 
识下载量监测与管理。提高大学体育教学效果监测力度。 加强大学体育课程教师教学研究团队的有机结合, 实现教 学经验的科学传授, 促进青年教师业务水平的提高。促进 大学体育课程网络平台建设, 提高资源应用效益, 优化大 学体育课程体系, 避免政府对高等教育的重复投入, 节省 办学经费, 提高办学效益, 使受教育者能平等地获得受教 育和发展的机会, 使教育信息资源得到充分的利用, 并发 挥其最大的教育效益、社会效益和经济效益。

\section{2. 建议}

大学体育课程的协同创新与资源共享要整体布局。做 到服务意识为先, 注重技术性、科研性、交互性、共享性, 努力挖掘各学科教育、教学、教研新成果; 在教育信息化 基础设施建设、资源建设、信息技术与课程整合的基层实 践进程中, 努力优化网络教育资源。

政府引导建立大学体育课程教学资源的战略联盟。战 略联盟院校同仁对大学体育课程优质教育资源的部分开 发, 如果全部开发其优质资源, 还需要财力、物力、人力 资源的帮助, 教育主管部门 (如教育厅) 行政指令或者协 调参与其中, 对本课题的研究必将起到激励作用, 对本地 区高校体育教学质量产生深远的影响。

优化高校体育教学管理机制。高校体育部门应加快自 身的变革, 按照合理分工、责任明确、上下协调, 科学管 理的原则 [14], 尽快建立和完善高校体育的现代管理制度。 同时要进行体育部门的业务流程重组, 积极进行体育组织 结构变革, 加强高校体育文化建设, 全面实施组织管理信 息化, 优化管理手段和管理方法, 为高校体育教学体制营 造良好的管理环境。从高校体育的发展战略和全局出发, 变革传统的信息管理体制, 把高校体育中的所有信息部门 与其功能整合在一起, 以实现大学体育教学管理的科学化、 制度化和信息化。

\section{参考文献}

[1] 伦玮, 李朝福, 区域性高校体育网络教育资源共享研究综 述 $[\mathrm{J}]$ ，当代体育科技，2014年（第4卷）第30期。
[2] 尚长景、程千秋, 高校体育课程改革热点解析与展望 $[\mathrm{J}]$, 当代体育科技，2016年 (第6卷) 第33期。

[3] 孙毅、宋艳红、林家润、陈庆峰、高强, 大学城体育课程 资源共享初探 $[J]$, 济宁医学院学报, 2014年8月第 37 卷第4 期。

[4] 李国玲, 大学城体育课程资源共享路径研究 $[\mathrm{J}]$, 当代体育 科技, 2016 年(第 6 卷)第 36 期。

[5] 汤其成, 周继良, 大学协同创新: 制约因素与改进思路 [J], 煤炭高等教育，2012年5月第30卷第3期

［6］郡云飞, 杨晓波, 邓龙江, 杜欣, 高校协同创新平台的构 建研究 $[J]$, 电子科技大学学报 (社科版) 2012年（第14 卷) 第4期。

[7] 唐阳, 关于高校开展协同创新的思考 $[\mathrm{J}]$, 中国高校科技, 2012年7月。

[8] 薛传会, 论高等学校的协同创新及其战略重点 $[J]$, 高校 教育管理, 2012 年11月第6卷第6期。

[9] 任海, 王凯珍等, 体育资源利用的改革与体育资源配置改 革的法规平台 $[J]$, 天津体育学院学报, 2002年第17卷第2 期。

[10] 叶仕满, 协同创新: 高校提升创新能力的战略选择 $[\mathrm{J}]$, 中国高校科技，2012年3月。

[11] 鲁钊阳, 高校教学资源共建共享的机制与模式研究一一以 重庆市大学联盟为例 $[J]$, 重庆高教研究, 2016年5月第4 卷第3期。

[12] 胡建华, 精品资源共享课程建设视野下高校课程理论教学 与实践教学协同创新探析 $[\mathrm{J}]$, 重庆第二师范学院学报, 第28卷第5期，2015年9月。

[13] 胡小善, 协同创新视角下高校体育大课程体系建设的研究 [ $J]$ ，山东体育科技, 2014年10月第36卷第5期。

[14] 孙晋海, 我国高校体育学学科发展战略研究 [D], 苏州大学 博士论文，2015年3月。 